\title{
Radiosensitive SCID patients with Artemis gene mutations show a complete B-cell differentiation arrest at the pre-B-cell receptor checkpoint in bone marrow
}

Jeroen G. Noordzij, Nicole S. Verkaik, Mirjam van der Burg, Lieneke R. van Veelen, Sandra de Bruin-Versteeg, Wouter Wiegant, Jaak M. J. J. Vossen, Corry M. R. Weemaes, Ronald de Groot, Malgorzata Z. Zdzienicka, Dik C. van Gent, and Jacques J. M. van Dongen

Severe combined immunodeficiency disease (SCID) can be immunologically classified by the absence or presence of $\mathrm{T}, \mathrm{B}$, and natural killer (NK) cells. About $30 \%$ of T-B-NK+ SCID patients carry mutations in the recombination activating genes (RAG). Some $\mathrm{T}^{-} \mathrm{B}^{-} \mathrm{NK}^{+} \mathrm{SCID}$ patients without $R A G$ gene mutations are sensitive to ionizing radiation, and several of these radiosensitive (RS) SCID patients were recently shown to have large deletions or truncation mutations in the Artemis gene, implying a role for Artemis in DNA double-strand break (dsb) repair. We identified 5 RS-SCID patients without RAG gene mutations, 4 of them with Artemis gene mutations. One patient had a large genomic deletion, but the other 3 patients carried simple missense mutations in conserved amino acid residues in the SNM1 homology domain of the Artemis protein. Extrachromosomal V(D)J recombination assays showed normal and precise signal joint formation, but inefficient coding joint formation in fibroblasts of these patients, which could be complemented by the wild-type Artemis gene. The cells containing the missense mutations in the SNM1 homology domain had the same recombination phenotype as the cells with the large deletion, indicating that these amino acid residues are indispensable for Artemis function. Immunogenotyping and immunophenotyping of bone marrow samples of 2 RS-SCID patients showed the absence of complete $V_{H}-J_{H}$ gene rearrangements and consequently a complete B-cell differentiation arrest at the pre-B-cell receptor checkpoint-that is, at the transition from $\mathrm{Cylg}^{-}{ }^{-}$pre-B-I cells to $\mathrm{Cylg}_{\mu^{+}}$pre-B-II cells. The completeness of this arrest illustrates the importance of Artemis at this stage of lymphoid differentiation. (Blood. 2003;101:1446-1452)

(C) 2003 by The American Society of Hematology

\section{Introduction}

Severe combined immunodeficiency disease (SCID) is clinically characterized by opportunistic infections, protracted diarrhea, and failure to thrive. ${ }^{1}$ Patients generally die within the first year of life unless treated with bone marrow (BM) transplantation. Other treatment options include enzyme substitution in case of adenosine deaminase-deficient SCID and gene therapy in case of common $\gamma$ chain-deficient X-linked SCID. ${ }^{2}$

Although SCID consists of a heterogeneous group of diseases, it is immunologically characterized by the absence or dysfunctioning of T lymphocytes. SCID can be subdivided based on the additional presence or absence of B lymphocytes and natural killer (NK) cells in peripheral blood (PB). A number of $\mathrm{T}^{-} \mathrm{B}^{-} \mathrm{NK}^{+} \mathrm{SCID}$ patients were shown to have mutations in the recombination activating genes (RAG1 and RAG2). ${ }^{3}$ However, not all patients with $\mathrm{T}^{-} \mathrm{B}^{-} \mathrm{NK}^{+}$ SCID have mutations in the $R A G$ genes. Subsequently, it was shown that fibroblasts of several $\mathrm{T}^{-} \mathrm{B}^{-} \mathrm{NK}^{+}$SCID patients without $R A G$ gene mutations were sensitive to ionizing radiation and thus likely to have a defect in DNA double-strand break (dsb) repair. ${ }^{4}$
During the process of immunoglobulin (Ig) and T-cell receptor (TCR) gene recombination in differentiating lymphocytes, the RAG proteins introduce DNA dsb's, which are repaired via nonhomologous end joining (NHEJ). ${ }^{5}$ NHEJ requires active DNAdependent protein kinase (DNA-PK), which consists of Ku70, $\mathrm{Ku} 80$, and the catalytic subunit (DNA-PK $\mathrm{Cs}_{\mathrm{cs}}$ ). The DNA-PK protein complex functions as a DNA damage sensor, with Ku70 and Ku80 forming a heterodimer that binds to DNA ends, while DNA-PK has serine and threonine protein kinase activity. ${ }^{6}$ In the final phase, the 2 broken DNA ends are ligated by the DNA ligase IV-XRCC 4 complex. ${ }^{7,8}$ However, it was shown that a number of radiosensitive (RS) $\mathrm{T}^{-} \mathrm{B}^{-} \mathrm{NK}^{+} \mathrm{SCID}$ patients without mutations in the $R A G$ genes did not suffer from mutations in any of these 5 DNA dsb repair components. ${ }^{4}$ Recently, a new gene involved in the pathogenesis of RS-SCID was identified and named Artemis. ${ }^{9,10}$ The Artemis protein can be phosphorylated by the DNA-PK complex, and the Artemis-DNA-PK complex is able to open hairpin-sealed coding ends and to process $5^{\prime}$ and $3^{\prime}$ overhangs. ${ }^{11}$ Several different large
From the Department of Immunology, Erasmus MC/University Medical Center Rotterdam, The Netherlands; Department of Cell Biology and Genetics, Erasmus MC/University Medical Center Rotterdam, The Netherlands Department of Pediatrics, Division of Immunology and Infectious Diseases, Erasmus MC/University Medical Center Rotterdam, The Netherlands Department of Pediatrics, Leiden University Medical Center, The Netherlands Department of Pediatrics, University Medical Center Nijmegen - St Radboud, The Netherlands; Department of Radiation Genetics and Chemical Mutagenesis, Leiden University Medical Center, The Netherlands; Department of Radiation Oncology, Erasmus MC/University Medical Center Rotterdam, The Netherlands; and Department of Molecular Cell Genetics, the Ludwik Rydygier University of Medical Sciences, Bydgoszcz, Poland.

Submitted June 6, 2002; accepted September 22, 2002. Prepublished online as

\section{Blood First Edition Paper, October 24, 2002; DOI 10.1182/blood-2002-01-0187.}

Supported by the Revolving Fund 2000 of the University Hospital Rotterdam, the Dutch Cancer Society/Koningin Wilhelmina Fonds (grants EUR 98-1775 and EMCR 2002-2734), and the Netherlands Scientific Organization (NWO grant AGIKO 920-03-089).

Reprints: J. J. M. van Dongen, Department of Immunology, Erasmus MC/University Medical Center Rotterdam, Dr Molewaterplein 50, 3015 GE Rotterdam, The Netherlands; e-mail: vandongen@immu.fgg.eur.nl.

The publication costs of this article were defrayed in part by page charge payment. Therefore, and solely to indicate this fact, this article is hereby marked "advertisement" in accordance with 18 U.S.C. section 1734.

(C) 2003 by The American Society of Hematology 
deletions and truncation mutations have been identified as diseasecausing Artemis mutations. , $^{12}$

We studied 5 RS-SCID patients (from 4 families) without $R A G$ gene mutations and found that 4 of them had mutations in the Artemis gene. Immunophenotyping and immunogenotyping of BM samples from 2 RS-SCID patients with Artemis gene mutations provided additional information about the role of Artemis during precursor B-cell differentiation.

\section{Patients, materials, and methods}

\section{Cell samples}

We received $\mathrm{PB}$ and/or BM samples and/or fibroblasts from $32 \mathrm{~T}^{-} \mathrm{B}^{-} \mathrm{NK}^{+}$ SCID patients. These patients were analyzed for the presence of mutations in the $R A G$ genes. ${ }^{13}$ Fibroblasts from $13 \mathrm{~T}^{-} \mathrm{B}^{-} \mathrm{NK}^{+}$SCID patients without mutations in the $R A G$ genes were analyzed for sensitivity to ionizing radiation.

BM samples from $\mathrm{T}^{-} \mathrm{B}^{-} \mathrm{NK}^{+}$SCID patients were subjected to FicollPaque (density, $1.077 \mathrm{~g} / \mathrm{mL}$ ) (Pharmacia, Uppsala, Sweden) density centrifugation. The recovered mononuclear cells (MCs) were frozen and stored in liquid nitrogen and thawed later for flow cytometric immunophenotyping studies. Granulocytes were used for DNA extraction.

All cell samples were obtained according to the informed consent guidelines of the medical ethics committees of the Erasmus MC/University Medical Center Rotterdam and the Leiden University Medical Center.

\section{Sensitivity of fibroblasts to ionizing radiation}

Primary skin fibroblasts in exponential growth were trypsinized, and 500 to 2000 cells (5 000 to 80000 cells for the highest doses) were seeded into $10-\mathrm{cm}$ plastic dishes ( 2 dishes per dose, 3 for nonirradiated control) and irradiated at room temperature at a dose of approximately $2.7 \mathrm{~Gy} / \mathrm{min}(200$ $\mathrm{kV}, 4.0 \mathrm{~mA}$ ). After 12 to 14 days, the cells were rinsed with $0.9 \% \mathrm{NaCl}$ and stained with $0.25 \%$ methylene blue for survival assessment. At least 3 independent survival experiments were performed for each sample.

\section{Messenger RNA and DNA isolation and CDNA reaction}

DNA was extracted from granulocytes or fibroblasts using the QIAamp Blood kit (Qiagen, Chatsworth, CA). ${ }^{14}$ Total RNA was isolated from BMMCs or fibroblasts using the GenElute Mammalian RNA kit (SigmaAldrich, St Louis, MO). Complementary DNA was prepared from mRNA as described before, using random hexamers and Superscript reverse transcriptase (Life Technologies, Paisley, United Kingdom). ${ }^{15}$

\section{PCR amplification and analysis of Ig gene rearrangements}

Polymerase chain reaction (PCR) was performed as described previously. ${ }^{15}$ In each $100-\mu \mathrm{L}$ PCR reaction, 0.1 to $1 \mu \mathrm{g}$ cDNA, 10 to $12.5 \mathrm{pmol}$ of $5^{\prime}$ and 3' oligonucleotides, and 1 unit of AmpliTaq gold polymerase (Applied Biosystems, Foster City, CA) were used. Oligonucleotides for amplification of the Artemis and Ig heavy chain $(I G H)$ gene rearrangements $\left(\mathrm{V}_{\mathrm{H}^{-}} \mathrm{J}_{\mathrm{H}}\right.$ and $\mathrm{D}_{\mathrm{H}^{-}} \mathrm{J}_{\mathrm{H}}$ ) were published before. ${ }^{10,16,17}$ PCR conditions were 7 minutes at $95^{\circ} \mathrm{C}$, followed by 45 seconds at $94^{\circ} \mathrm{C}, 90$ seconds at $55^{\circ} \mathrm{C}$ to $60^{\circ} \mathrm{C}, 2$ minutes at $72^{\circ} \mathrm{C}$ for 40 cycles, followed by a final extension step ( 7 minutes at $72^{\circ} \mathrm{C}$ ). DNA from BMMCs was analyzed for rearrangements of $\mathrm{D}_{\mathrm{H}} 1$, $\mathrm{D}_{\mathrm{H}} 2, \mathrm{D}_{\mathrm{H}} 3, \mathrm{D}_{\mathrm{H}} 4, \mathrm{D}_{\mathrm{H}} 5, \mathrm{D}_{\mathrm{H}} 6, \mathrm{D}_{\mathrm{H}} 7, \mathrm{~V}_{\mathrm{H}} 1 / 7, \mathrm{~V}_{\mathrm{H}} 2, \mathrm{~V}_{\mathrm{H}} 3, \mathrm{~V}_{\mathrm{H}} 4, \mathrm{~V}_{\mathrm{H}} 5$, and $\mathrm{V}_{\mathrm{H}} 6$ to $\mathrm{J}_{\mathrm{H} \cdot}{ }^{13}$

\section{Fluorescent sequencing reaction and analysis}

PCR products of Artemis were purified using QIAquick PCR purification kit (Qiagen). Cloned $I G H$ gene rearrangements were isolated via GenElute Plasmid MiniPrep Kit (Sigma-Aldrich). A 2 to $9 \mu \mathrm{L}$ template was sequenced with $5 \mu \mathrm{L}$ BigDye terminator mix (Applied Biosystems) using 3.3 to 6.6 pmol sequencing primers. All sequencing was performed as described before ${ }^{16}$ and run on an ABI Prism 377 fluorescent sequencer (Applied Biosystems).

\section{Western blot analysis of proteins involved in DNA dsb repair}

Protein samples from fibroblasts were separated on an $11 \%$ polyacrylamide gel and analyzed by Western blotting. The expression of Mre11 (rabbit polyclonal antibody [Ab] no. 2244) ${ }^{18}$ XRCC4 (rabbit polyclonal Ab NIH14), Ku70 (goat polyclonal Ab C19, Santa Cruz Biotechnology, Santa Cruz, CA) and Ku80 (goat polyclonal Ab C20, Santa Cruz Biotechnology), DNA-PK ${ }_{\mathrm{cs}}$ (rabbit polyclonal Ab no. 2129), ligase IV (goat polyclonal Ab T20, Santa Cruz Biotechnology), ATM (gift from Dr S. Jackson, Wellcome Trust and Cancer Research, Cambridge, United Kingdom), and NBS1 (p95NBS1, Calbiochem, San Diego, CA) proteins was analyzed.

\section{Analysis of NHEJ via transfection of linearized DNA constructs}

Linearized DNA constructs with homologous ends (ATCAGC sequence) were transfected into fibroblasts of RS-SCID patients and fibroblasts of a patient with a mutation in DNA ligase IV (180BR) as described before. ${ }^{19}$ Newly formed junctions were PCR amplified, and the relative use of a particular microhomology was assayed by digestion with the restriction enzyme BstXI (Figure 2). ${ }^{19}$

\section{Extrachromosomal VDJ recombination assay}

For analysis of signal and coding joint formation in the different RS-SCID fibroblasts with Artemis mutations, $2 \mu \mathrm{g} R A G 1$ and $2 \mu \mathrm{g} R A G 2$ expression vectors together with $1 \mu \mathrm{g}$ of the recombination substrate pGG49 or pGG51, ${ }^{20}$ each containing 2 recombination signal sequence (RSS) elements, were transfected into fibroblasts using Fugene Transfection Reagent (Roche Diagnostics, Indianapolis, IN) as described before. ${ }^{13}$ Transfected cells were cultured for 2 days at $37^{\circ} \mathrm{C}$ and $5 \% \mathrm{CO}_{2}$ before isolation of extrachromosomal DNA. Upon V(D)J recombination, the sequence between the RSS elements is deleted, after which coding (pGG51) or signal joint (pGG49) formation can be detected by PCR analysis of the newly formed junctions (Figure 3). DNA recovered from these transfection experiments was resuspended in $20 \mu \mathrm{L} \mathrm{H}_{2} \mathrm{O}$, of which $1 \mu \mathrm{L}$ was used for PCR analysis. First, DNA was predigested with $\mathrm{Cla}$ I to reduce the signal derived from nonrecombined V(D)J substrate. To amplify the coding or signal joints, a nested PCR of $2 \times 25$ cycles was performed. The first round of PCR was performed with oligonucleotides NV09F and DG147 (Table 1) in a total volume of $50 \mu \mathrm{L}$. Subsequently, $1 \mu \mathrm{L}$ of this PCR reaction was used as a template for the second round of PCR using oligonucleotides NV08F and FM30, of which FM30 was radioactively labeled with $\gamma^{32} \mathrm{P}$-adenosine triphosphate (ATP). The PCR conditions were the same as described before. ${ }^{13} \mathrm{PCR}$ fragments were separated on a $6 \%$ polyacrylamide gel, and products were visualized by phosphorimaging. ${ }^{13}$

\section{Artemis complementation studies}

To determine whether the recombination defect could be complemented, either wild-type (wt) Artemis or a mutant Artemis expression construct was cotransfected with the $R A G 1$ and $R A G 2$ expression vectors and the coding joint recombination substrate pGG51 into fibroblasts of the RS-SCID patients with Artemis gene mutations. The wt Artemis expression construct

Table 1. Primers used for extrachromosomal VDJ recombination assays and for generation of the wt Artemis expression construct

\begin{tabular}{ll}
\hline Primer & \multicolumn{1}{c}{ Sequence } \\
\hline NV09F & 5'-CGTCTTCAAGAATTGTCGATGAATTCC-3' \\
DG147 & 5'-TACATTGAGCAACTGACTGAAATGCC-3' \\
NV08F & 5'-AACTAGTTAACTATACGCAGCTTGGC-3' \\
FM30 & 5'-CTCCATTTTAGCTTCCTTAGCTCCTG-3' \\
DG238 & 5'-TCCGCTCGAGGCGGCGCTATGAGTTCTTTCG-3' \\
DG239 & 5'-TCCGACGCGTTGGTATCTAAGAGTGAGCATTTTCTT-3' \\
\hline
\end{tabular}




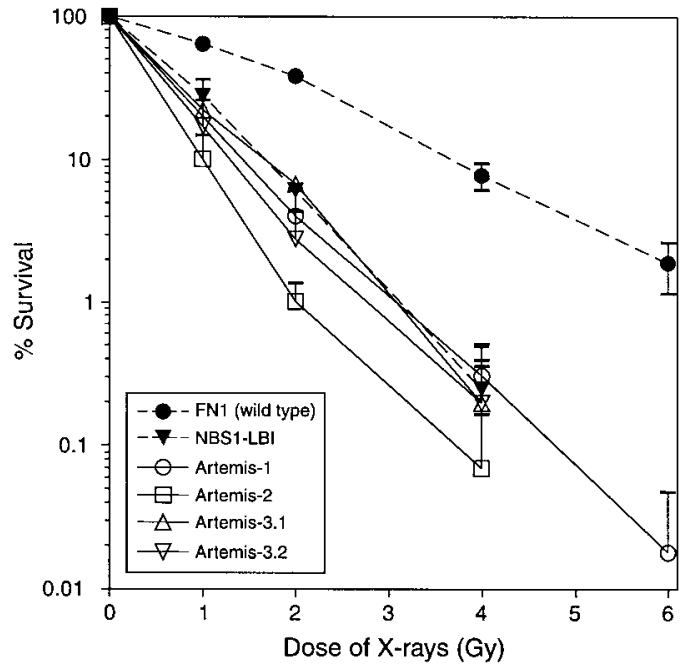

Figure 1. Clonogenic survival assay of fibroblasts after ionizing radiation Fibroblasts from $5 \mathrm{~T}^{-} \mathrm{B}^{-} \mathrm{NK}^{+} \mathrm{SCID}$ patients from 4 families without $R A G$ mutations were radiosensitive. Data from the 4 patients with Artemis gene mutations are shown NBS indicates Nijmegen breakage syndrome. Each survival curve represents the mean of at least 3 independent experiments. Error bars represent standard errors of the mean.

was made by performing a PCR with the DG238 and DG239 oligonucleotides (Table 1) on Hela cDNA. This 2.1-kb PCR product was digested with XhoI and MluI and cloned into the XhoI and MluI sites of plasmid pMS127B. ${ }^{21}$ The point mutations of patients Artemis-2 and Artemis-3.1 were cloned by performing this same PCR on cDNA generated from the fibroblasts of these patients. This $2.1-\mathrm{kb}$ fragment was digested with Nsi and EcoRV, after which the 500-bp fragment containing the point mutations was exchanged for the NsiI-EcoRV part of the wt construct.

\section{Flow cytometric analysis of BM samples from RS-SCID patients with Artemis gene mutations}

Fifty microliter aliquots of thawed BMMCs $\left(10 \times 10^{6}\right.$ cells per milliliter $)$ were incubated for 10 minutes at room temperature with combinations of optimally titrated monoclonal antibody (MAb): $50 \mu \mathrm{L}$ fluorescein isothiocyanate (FITC)-conjugated MAb, $50 \mu \mathrm{L}$ phycoerythrin (PE)-conjugated MAb, $50 \mu \mathrm{L}$ peridinin chlorophyll protein (PerCP) cyanin (CY) 5.5conjugated $\mathrm{MAb}$, and $50 \mu \mathrm{L}$ allophycocyanin (APC)-conjugated $\mathrm{MAb}$ were used to detect membrane-bound antigens. After incubation, the cells were washed and further processed depending on the type of quadruple labeling. 22,23

Quadruple labelings for membrane-bound antigens were directly analyzed by flow cytometry using FACSCalibur (Becton Dickinson, San Jose, CA). For quadruple labelings involving intracellular staining of cytoplasmic (Cy) CD79a, CyIg $\mu, \mathrm{CyV}$ preB,${ }^{24}$ and intranuclear staining of terminal deoxynucleotidyl transferase (TdT), we first performed the membrane labelings, followed by permeabilization of the BM cells using IntraPrep Permeabilization Reagent (Immunotech, Marseille, France) and subsequent intracellular staining. ${ }^{25,26}$

\section{Results \\ Patient characteristics, Western blot analysis, and disease-causing Artemis gene mutations}

We analyzed material from $32 \mathrm{~T}^{-} \mathrm{B}^{-} \mathrm{NK}^{+}$SCID patients for the presence of $R A G$ gene mutations, both at the genomic and at the transcriptional level. We could not detect mutations in the $R A G$ genes in 23 patients $(72 \%)$. From $13 \mathrm{~T}^{-} \mathrm{B}^{-} \mathrm{NK}^{+}$SCID patients without $R A G$ mutations, fibroblasts were available and analyzed for sensitivity to ionizing radiation in a clonogenic survival assay.

Fibroblasts from $5 \mathrm{~T}^{-} \mathrm{B}^{-} \mathrm{NK}^{+}$SCID patients from 4 families showed a 2-fold to 3-fold increased sensitivity toward X-rays, compared with wild-type (wt) primary fibroblasts (FN1). The degree of the observed X-ray sensitivity was similar to fibroblasts derived from a patient with Nijmegen breakage syndrome (NBS1LBI) (Figure 1). Western blot analysis of Mre11, XRCC4, Ku70, $\mathrm{Ku} 80, \mathrm{DNA}_{\mathrm{PS}}$, and ligase IV proteins derived from fibroblasts from the 5 RS-SCID patients showed normal expression (data not shown). Finally, genomic sequencing of Artemis exons (including splice sites) revealed mutations in 4 of the 5 RS-SCID patients. The clinical characteristics of the 4 patients with Artemis gene mutations are summarized in Table 2.

Patient Artemis-1 showed a homozygous deletion of exons 10, 11, and 12 of the Artemis gene. At the mRNA level, exon 9 was coupled to exon 13, resulting in a frameshift and premature stop at codon 269 in the SNM1 homology domain (numbering according to Moshous et al). ${ }^{10}$

Patient Artemis-2 showed a homozygous G $>\mathrm{T}$ mutation at position 47 in exon 5 of the Artemis gene. This resulted in mutation of a glycine to valine residue at position 111 in the SNM1 homology domain of the Artemis protein. We did not identify this point mutation in 18 healthy controls. Furthermore, glycine at position 111 is highly conserved between yeast PSO2, mouse SNM1, human SNM1A, and human SNM1B proteins and therefore is likely to represent an essential amino acid (aa). ${ }^{27}$

Patients Artemis-3.1 and -3.2 showed a homozygous $G>A$ mutation at position 42 in exon 6 of the Artemis gene. This resulted in mutation of a glycine to glutamic acid residue at position 128 in the SNM1 homology domain of the Artemis protein. We did not identify this point mutation in 14 healthy controls. Furthermore, glycine at position 128 is highly conserved between yeast PSO2, mouse SNM1, human SNM1A, and human SNM1B proteins and therefore likely to represent an essential aa. ${ }^{27}$ Because the parents of patients Artemis-3.1 and -3.2 had a nonconsanguineous relationship, we investigated whether the point mutation was really homozygous. We excluded a large deletion (containing exon 6) of one allele by Southern blot analysis of the Artemis gene using a PCR-based exon 6 probe (data not shown). We did not find a lower level of hybridization (normalized to Igк J5) in the patients relative

Table 2. Clinical characteristics of the 4 RS-SCID patients with Artemis gene mutations

\begin{tabular}{|c|c|c|c|c|c|c|c|}
\hline Patient & Sex & $\begin{array}{c}\text { Age at } \\
\text { diagnosis }\end{array}$ & Diagnosis & $\begin{array}{l}\text { Consanguinity of } \\
\text { parents }\end{array}$ & $\begin{array}{l}\text { Infections } \\
\text { at diagnosis }\end{array}$ & Treatment & Outcome \\
\hline Artemis-1 & $\mathrm{F}$ & $5 \mathrm{mo}$ & $\mathrm{T}^{-} \mathrm{B}^{-} \mathrm{NK}^{+}$ & Yes & PCP & BMT & Alive \\
\hline Artemis-2 & $\mathrm{F}$ & $5 \mathrm{mo}$ & Tlow $^{-} \mathrm{NK}^{+*}$ & Yes & $\mathrm{PCP}, \mathrm{CMV}$ & BMT & No B-cell take; receives IVIG \\
\hline Artemis-3.1 & M & $4 \mathrm{mo}$ & $\mathrm{T}^{-} \mathrm{B}^{-} \mathrm{NK}^{+}$ & No & Persistent VZV infection & BMT & Died from disseminated infections \\
\hline Artemis-3.2 & M & $1 d$ & $\mathrm{~T}^{-} \mathrm{B}^{-} \mathrm{NK}^{+}$ & No & None & BMT & Died from multiorgan failure \\
\hline
\end{tabular}

PCP indicates Pneumocystis carinii pneumonia; BMT, BM transplantation; CMV, cytomegalovirus; IVIG, intravenous Ig substitution; and VZV, varicella-zoster virus.

*Maternal T lymphocytes were shown to be present in her PB but did not cause graft-versus-host disease due to identical HLA. 
A
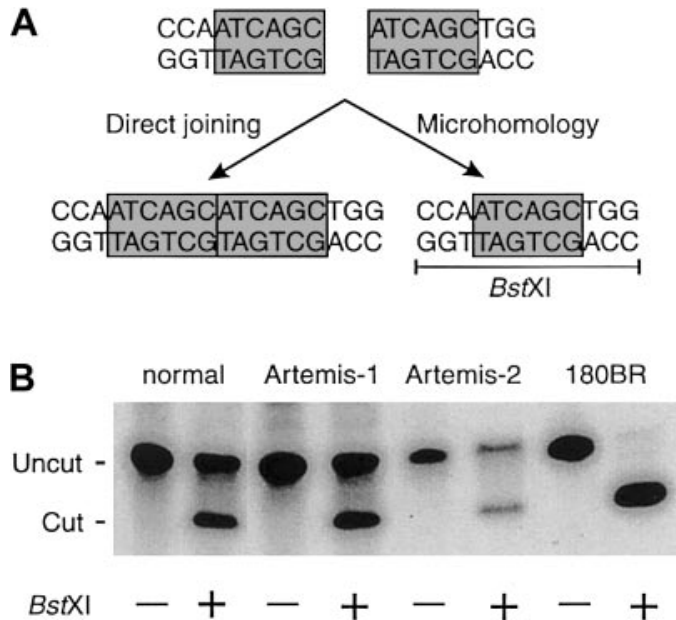

Figure 2. Fibroblasts of a healthy control and RS-SCID patients with mutations in the Artemis gene show equal usage of direct joining and microhomology when rejoining linearized DNA constructs. (A) Linearized DNA constructs with homologous ends (ATCAGC) can be rejoined via direct joining or via microhomology. Joining via microhomology results in the generation of a BstXI restriction site (CCAN $\left.{ }_{6} T G G\right)$. (B) In contrast to normal fibroblasts and fibroblasts from patients with an Artemis mutation, fibroblasts with a mutation in DNA ligase IV (180BR) show complete absence of direct joining and full usage of the microhomology pathway.

to a healthy control, indicating that these patients are homozygous for the point mutation.

In addition to the full-length transcripts, one of the Artemis-3 patients showed alternatively spliced transcripts in which exon 4 was spliced to exon 6. Sequencing analysis of the alternatively spliced transcripts showed the presence of the disease-causing $\mathrm{G}>\mathrm{A}$ mutation in exon 6 , fully consistent with the homozygous mutation. Such alternatively spliced Artemis transcripts were not found in patient Artemis-2. No mutations were present in the donor and acceptor splice sites of any Artemis exon in the 4 studied patients.

\section{Additional nondisease-causing mutations in the Artemis gene}

The entire Artemis gene was sequenced in all 4 RS-SCID patients with Artemis mutations to exclude the presence of additional mutations. We identified a total of 4 additional alterations compared with the published sequence. Two base changes were present in all 4 RS-SCID patients analyzed and were therefore likely to represent polymorphisms or sequencing errors in the published sequence. The first alteration concerned a $\mathrm{G}>\mathrm{T}$ change at position 522 in exon 14 of the Artemis gene. This alteration resulted in a change from a valine to leucine residue at position 553 outside the SNM1 homology domain of the Artemis protein. The second alteration concerned a $\mathrm{C}>\mathrm{T}$ change at position 653 in exon 14 of the Artemis gene, which did not result in an aa substitution.

We identified another silent alteration at position 106 in exon 8 of the Artemis gene (a T $>\mathrm{C}$ change) in patients Artemis-3.1 and -3.2. Finally, patient Artemis-1 with the large deletion carried a homozygous $\mathrm{A}>\mathrm{G}$ change at position 50 in exon 9 of the Artemis gene. This alteration resulted in a change from the basic aa histidine to the basic aa arginine at position 236 in the SNM1 homology domain. We did not identify this point mutation in 12 healthy controls.

\section{Dsb repair}

Mutation of $\mathrm{Ku} 80, \mathrm{DNA}_{\mathrm{PS}}$, XRCC4, or DNA ligase IV leads to a shift from precise joining to microhomology-directed joining in

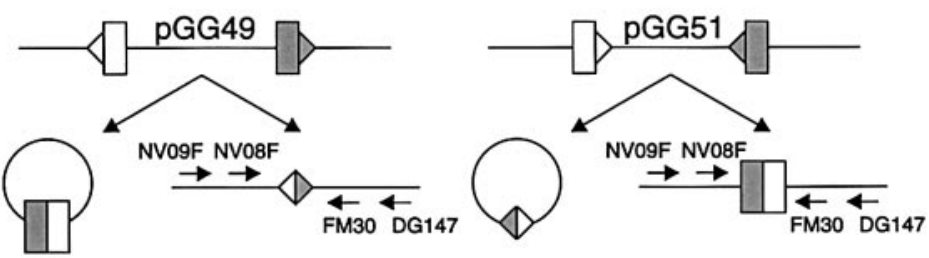

Figure 3. $V(D) J$ recombination assay in RS-SCID fibroblasts with signal Artemis gene mutations. (A) Schematic representation of the signal joint assay (sj) and the coding joint assay (cj) in which the recombination substrates pGG49 and pGG51 were used, respectively. Recombination signal sequences are depicted as triangles and the flanking coding sequence as rectangles. The signal joints are retained in the recombination substrate when pGG49 is used, while coding joints are retained in the recombination substrate when pGG51 is used. Signal joints and coding joints were detected with nested PCR analysis using a ${ }^{32} \mathrm{P}$-labeled primer (see "Materials and methods"). (B) Primary fibroblasts of Artemis-1 and Artemis-2 transfected with RAG1 and RAG2 expression constructs and the recombination substrate formed signal joints but no coding joints. FN1 control primary fibroblasts can form both signal joints and coding joints. Defective coding joint formation in Artemis-1 and Artemis-2 could be complemented by cotransfection of the wt Artemis expression construct (+Art). (C) SV40-immortalized fibroblasts of Artemis-3 were also able to form signal joints but not coding joints. Like in Artemis-1 and Artemis-2, coding joint formation occurred upon cotransfection of the wt Artemis expression construct. SV40-immortalized MCR5 fibroblasts were used as control.
B

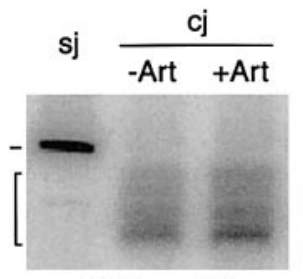

FN1 control

C

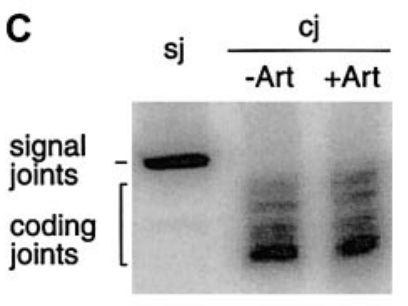

MRC5 control

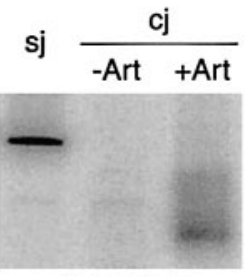

Artemis-1

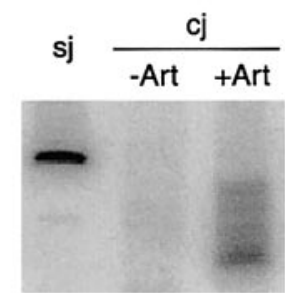

Artemis-3

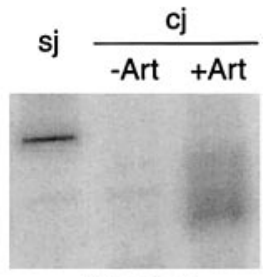

Artemis-2 
Table 3. Percentage of B cells within the BM lymphocyte gate

\begin{tabular}{lccccc}
\hline & \multicolumn{2}{c}{ CD22 ${ }^{+}$B cells, \% } & & \\
\cline { 2 - 3 } & $\begin{array}{c}\text { Precursor } \\
\text { B cells* }\end{array}$ & $\begin{array}{c}\text { Mature } \\
\text { B cells }\end{array}$ & $\begin{array}{c}\text { CD79 }^{+} \\
\text {B cells, \% }\end{array}$ & $\begin{array}{c}\text { CD19 }^{+} \\
\text {B cells, \% }\end{array}$ \\
\hline $\begin{array}{l}\text { Healthy children younger } \\
\text { than } 6 \text { y }(n=6)\end{array}$ & $31 \pm 10$ & $19 \pm 5$ & $53 \pm 10$ & $50 \pm 10$ \\
Artemis-1 & 3 & 0.004 & 1 & 1 \\
Artemis-2 & 23 & 0.006 & 17 & 16 \\
\hline
\end{tabular}

*The percentage of precursor B cells was calculated by subtracting the percentage of mature $\mathrm{SmlgM}^{+} / \mathrm{SmlgD}^{+} \mathrm{B}$ cells from the total percentage of CD22+ $\mathrm{B}$ cells.

mammalian cells. ${ }^{19}$ Therefore, we transfected linearized DNA constructs into fibroblasts of all 4 patients with Artemis gene mutations to analyze the use of direct joining and microhomology pathways. The Artemis-mutated cells showed equal usage of the direct joining and microhomology pathways (Figure 2), suggesting that Artemis is not involved in the ligation process itself.

$\mathrm{V}(\mathrm{D}) \mathrm{J}$ recombination also involves dsb repair by NHEJ. We analyzed coding and signal joint formation in fibroblasts of all 4 patients with Artemis gene mutations. In all cases we found normal levels of precise signal joint formation but absence of coding joint formation (Figure 3).

\section{Complementation of the coding joint formation defect by cotransfection of wt Artemis constructs}

The genomic deletion in patient Artemis-1, resulting in a premature stop codon, was most probably the disease-causing defect. However, we considered the possibility that the missense mutations in patients Artemis-2, -3.1, and -3.2 could represent polymorphisms. Therefore, we cotransfected the wt Artemis expression vector together with the RAG1 and RAG2 expression vectors and the recombination substrates into fibroblasts of the RS-SCID patients and analyzed the signal and coding joint formation. As shown in Figure 3, this resulted in complementation of the coding joint formation defect, thereby proving the disease-causing effect of the missense mutations in the Artemis gene. Furthermore, transfection of an Artemis expression vector containing the mutation of Artemis-3 could not complement coding joint formation in Artemis-2 fibroblasts and vice versa (data not shown).

\section{Ig gene rearrangements in BMMCs}

To study the capacity of mutated Artemis proteins to perform DNA dsb repair during human precursor B-cell differentiation in vivo, we isolated DNA from BMMCs and investigated the occurrence of incomplete $\mathrm{D}_{\mathrm{H}^{-}} \mathrm{J}_{\mathrm{H}}$ and complete $\mathrm{V}_{\mathrm{H}^{-}} \mathrm{J}_{\mathrm{H}}$ gene rearrangements. $\mathrm{BM}$ samples were available from patients Artemis-1 and Artemis-2. In both patients, incomplete $\mathrm{D}_{\mathrm{H}^{-}} \mathrm{J}_{\mathrm{H}}$ gene rearrangements could be amplified by PCR, but no complete $\mathrm{V}_{\mathrm{H}^{-}} \mathrm{J}_{\mathrm{H}}$ gene rearrangements could be detected.

Flow cytometric analysis of precursor B cells in BM of RS-SCID patients with Artemis gene mutations

BM samples from 2 RS-SCID patients with Artemis gene mutations (Artemis-1 and -2) were available and analyzed as described before. ${ }^{22,23}$ The percentage of B cells within the lymphocyte gate differed between the 2 RS-SCID patients with Artemis gene mutations (Table 3). In BM from healthy children, approximately $15 \%$ of the precursor B-cell compartment consisted of $\mathrm{CyIg} \mu-$ precursor B cells, distributed over pro-B cells and pre-B-I cells with a pro-B/pre-B-I ratio of $1.3 \pm 0.8$, whereas in BM from both RS-SCID patients with Artemis gene mutations, $100 \%$ of the precursor B-cell compartment was located in the pro-B and pre-B-I cell stages (Figures 4 and 5). Therefore, our results indicate that the differentiation arrest in the 2 RS-SCID patients with Artemis gene mutations resulted in a more than 6-fold relative accumulation of precursor B-cell subpopulations located before the transition from $\mathrm{CyIg} \mu^{-}$pre-B-I cells to $\mathrm{CyIg} \mu^{+}$pre-B-II cells, with an inverted pro-B/pre-B-I ratio of $0.6 \pm 0.7$ in the 2 RS-SCID patients with Artemis gene mutations.

\section{Discussion}

From $13 \mathrm{~T}^{-} \mathrm{B}^{-} \mathrm{NK}^{+} \mathrm{SCID}$ patients without $R A G$ mutations, fibroblasts were analyzed for sensitivity to ionizing radiation. We found 5 of these $13 \mathrm{~T}^{-} \mathrm{B}^{-} \mathrm{NK}^{+} \mathrm{SCID}$ patients to be RS, 4 of which contained Artemis mutations, indicating that Artemis mutation is the most common reason for RS-SCID. We did not find a founder effect in our patients. In accordance with the suggestion of

A
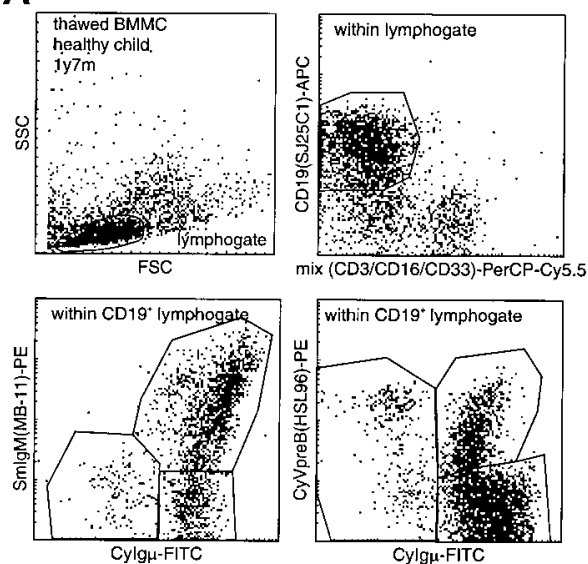

B
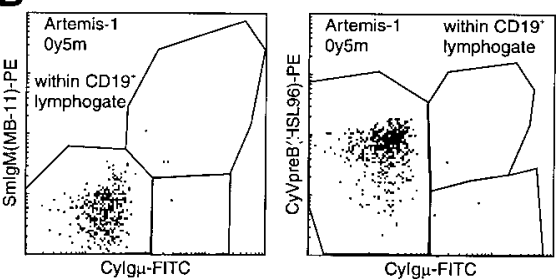

C

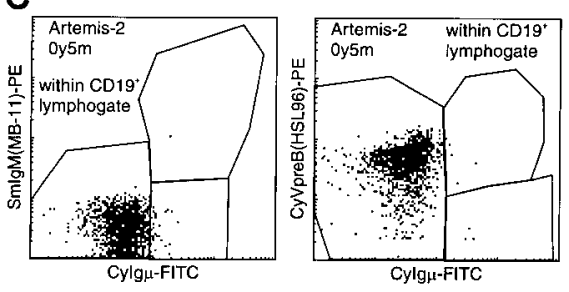

Figure 4. Flow cytometric analysis of CD19+ lymphocytes in BM from a healthy control and 2 RS-SCID patients with Artemis gene mutations. (A) Gating on $\mathrm{CD} 19^{+}$lymphocytes with exclusion of $\mathrm{CD}^{+} \mathrm{T}$ lymphocytes, CD16 ${ }^{+} \mathrm{NK}$ cells, and $\mathrm{CD}^{+}{ }^{+}$myeloid cells, resulting in a purified "B-cell gate" (upper panels). Within this B-cell gate, expression of cytoplasmic VpreB (CyVpreB), cytoplasmic Ig $\mu$ (Cylg $\mu$ ), and surface membrane $\operatorname{lgM}(\mathrm{SmlgM})$ can be evaluated (lower panels), showing several subsets in normal BM with most cells in the most mature $\left(\lg \mu^{+}\right)$precursor B-cell stages. (B-C) Patients Artemis-1 and -2 showed a complete arrest at the transition from Cylg $\mu^{-}$pre-B-I cells to Cylg $\mu^{+}$pre-B-Il cells. Although no Cylg $\mu$ expression was detected, virtually all CD19+ precursor B cells were positive fo CyVpreB. This is fully in line with the expression of CyVpreB in early precursor B cells. 
Figure 5. Composition of the precursor B-cell compartment in healthy controls and in the 2 studied RS-SCID patients with Artemis gene mutations. In contrast to healthy controls, the precursor B-cel compartment in the 2 RS-SCID patients with Artemis gene mutations showed a complete arrest at the transition of pre-B-I cells to pre-B-Il cells. The relative distribution between pro-B and pre-B-I cells was different in the 2 patients.

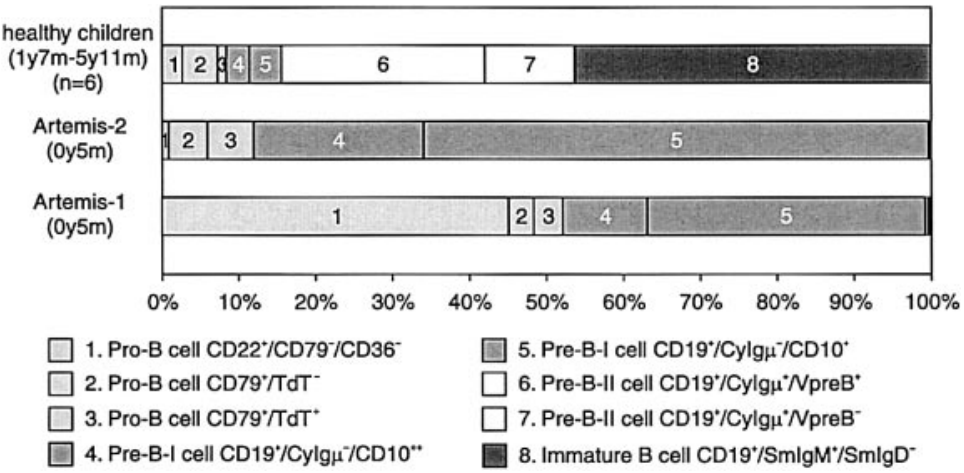

Moshous et $\mathrm{a}^{10}$ that the Artemis gene might represent a hot spot for gene deletion, we identified a large genomic deletion in patient Artemis-1. So far, none of the reported Artemis mutations were simple missense mutations, but the RS-SCID phenotype in patients Artemis-2, -3.1, and -3.2 was proven to be caused by aa substitutions in the SNM1 homology domain of the Artemis protein, because the coding joint formation defect in the fibroblast recombination assay of these RS-SCID patients could be complemented by cotransfection of the wt Artemis expression vector (Figure 3). The 2 point mutations were in evolutionary highly conserved aa residues in the SNM1 homology domain, suggesting that this domain is required for catalytic activity, probably the nuclease activity that can open the DNA hairpins at the coding ends.

Increased microhomology use in a plasmid recircularization assay proved to be highly diagnostic of mutations in the DNA-PK or ligase IV-XRCC4 complex. ${ }^{19}$ However, our 4 RS-SCID patients with mutations in the Artemis gene showed normal direct joining (Figure 2). This suggests that the Artemis protein functions in a different step of the end joining process. These results are consistent with the recent biochemical evidence that Artemis may be required for hairpin opening and DNA end processing. ${ }^{11}$

We previously described detection of $I G H$ gene rearrangements in human BMMCs as a parameter for in vivo RAG activity. ${ }^{13}$ Now we have used detection of $I G H$ gene rearrangements in BMMCs of Artemis-1 and Artemis-2 as a parameter for residual activity of the Artemis protein. The complete absence of normal coding joints in patient Artemis-1 is in line with the large genomic deletion, which results in a truncated Artemis protein with absence of part of the SNM1 homology domain. Patient Artemis-2 contained relatively high frequencies of precursor B cells (23\% of BM lymphocytes, Table 3), but we could detect only incomplete $\mathrm{D}_{\mathrm{H}^{-}} \mathrm{J}_{\mathrm{H}}$ rearrangements and no $\mathrm{V}_{\mathrm{H}^{-}} \mathrm{J}_{\mathrm{H}}$ gene rearrangements.

Flow cytometric evaluation of the BM precursor B-cell compartment in patients Artemis- 1 and -2 showed a complete arrest at the transition from $\mathrm{CyIg} \mu^{-}$pre-B-I cells to $\mathrm{CyIg} \mu^{+}$pre-B-II cells. The completeness of this B-cell differentiation arrest illustrates the importance of Artemis at this stage of lymphoid differentiation.

In conclusion, both deletions and missense mutations in the Artemis gene can cause RS-SCID with defective coding joint formation and lead to an early and complete B-cell differentiation block.

\section{Acknowledgments}

The authors thank Penny Jeggo for 180BR, Jean-Pierre de Villartay for communication of results before publication, Michael Lieber for the pGG49 and pGG51 constructs, Mauro Modesti for XRCC4 antisera, Steve Jackson for anti-ATM antiserum, R. E. E. van Lange for technical assistance, and $\mathrm{H}$. Karasuyama for making available the MAb HSL96 directed against the human VpreB protein.

\section{References}

1. Buckley RH. Primary immunodeficiency diseases due to defects in lymphocytes. N Engl J Med. 2000;343:1313-1324.

2. Cavazzana-Calvo M, Hacein-Bey S, de Saint Basile G, et al. Gene therapy of human severe combined immunodeficiency (SCID)-X1 disease. Science. 2000;288:669-672.

3. Schwarz K, Gauss GH, Ludwig L, et al. RAG mutations in human B cell-negative SCID. Science. 1996;274:97-99

4. Nicolas N, Moshous D, Cavazzana-Calvo M, et al. A human severe combined immunodeficiency (SCID) condition with increased sensitivity to ionizing radiations and impaired $\mathrm{V}(\mathrm{D}) \mathrm{J}$ rearrangements defines a new DNA recombination/repair deficiency. J Exp Med. 1998;188:627-634.

5. Van Gent DC, Hoeijmakers JH, Kanaar R. Chromosomal stability and the DNA double-stranded break connection. Nat Rev Genet. 2001;2:196206.

6. Smith GC, Jackson SP. The DNA-dependent protein kinase. Genes Dev. 1999;13:916-934.

7. Critchlow SE, Bowater RP, Jackson SP. Mammalian DNA double-strand break repair protein XRCC4 interacts with DNA ligase IV. Curr Biol. 1997;7:588-598.
8. Grawunder $U$, Wilm M, Wu X, et al. Activity of DNA ligase IV stimulated by complex formation with XRCC4 protein in mammalian cells. Nature. 1997;388:492-495.

9. Moshous D, Li L, Chasseval R, et al. A new gene involved in DNA double-strand break repair and $V(D) J$ recombination is located on human chromosome 10p. Hum Mol Genet. 2000;9:583-588.

10. Moshous D, Callebaut I, de Chasseval R, et al Artemis, a novel DNA double-strand break repair/ $\mathrm{V}(\mathrm{D}) \mathrm{J}$ recombination protein, is mutated in human severe combined immune deficiency. Cell. 2001; 105:177-186.

11. Ma Y, Pannicke U, Schwarz K, Lieber MR. Hairpin opening and overhang processing by an Artemis/ DNA-dependent protein kinase complex in nonhomologous end joining and $\mathrm{V}(\mathrm{D}) \mathrm{J}$ recombination. Cell. 2002;108:781-794.

12. Li L, Moshous D, Zhou Y, et al. A founder mutation in Artemis, an SNM1-like protein, causes SCID in Athabascan-speaking Native Americans. J Immunol. 2002;168:6323-6329.

13. Noordzij JG, Verkaik NS, Hartwig NG, De Groot R, Van Gent DC, Van Dongen JJM. N-terminal truncated human RAG1 proteins can direct T-cell receptor but not immunoglobulin gene rearrangements. Blood. 2000;96:203-209.

14. Verhagen OJHM, Wijkhuis AJM, Van der SluijsGelling AJ, et al. Suitable DNA isolation method for the detection of minimal residual disease by PCR techniques. Leukemia. 1999;13:1298-1299.

15. Van Dongen JJM, Macintyre EA, Gabert JA, et al. Standardized RT-PCR analysis of fusion gene transcripts from chromosome aberrations in acute leukemia for detection of minimal residual disease. Report of the BIOMED-1 Concerted Action: investigation of minimal residual disease in acute leukemia. Leukemia. 1999;13:1901-1928.

16. Szczepanski T, Pongers-Willemse MJ, Langerak AW, et al. Ig heavy chain gene rearrangements in T-cell acute lymphoblastic leukemia exhibit predominant DH6-19 and DH7-27 gene usage, can result in complete V-D-J rearrangements, and are rare in T-cell receptor $\alpha \beta$ lineage. Blood. 1999; 93:4079-4085.

17. Pongers-Willemse MJ, Seriu T, Stolz F, et al. Primers and protocols for standardized detection of minimal residual disease in acute lymphoblas tic leukemia using immunoglobulin and T cell receptor gene rearrangements and TAL1 deletions 
as PCR targets. Report of the BIOMED-1 Concerted Action: investigation of minimal residual disease in acute leukemia. Leukemia. 1999;13: 110-118.

18. de Jager M, Dronkert ML, Modesti M, Beerens CE, Kanaar R, van Gent DC. DNA-binding and strand-annealing activities of human Mre11: implications for its roles in DNA double-strand break repair pathways. Nucleic Acids Res. 2001;29: 1317-1325.

19. Verkaik NS, Esveldt-van Lange RE, van Heemst $\mathrm{D}$, et al. Different types of $\mathrm{V}(\mathrm{D}) \mathrm{J}$ recombination and end-joining defects in DNA double-strand break repair mutant mammalian cells. Eur J Immunol. 2002;32:701-709.

20. Gauss GH, Lieber MR. Mechanistic constraints on diversity in human $\mathrm{V}(\mathrm{D}) \mathrm{J}$ recombination. Mol Cell Biol. 1996;16:258-269.

21. Sadofsky MJ, Hesse JE, McBlane JF, Gellert M.
Expression and $\mathrm{V}(\mathrm{D}) \mathrm{J}$ recombination activity of mutated RAG-1 proteins. Nucleic Acids Res 1993;21:5644-5650.

22. Noordzij JG, De Bruin-Versteeg S, Verkaik NS, et al. The immunophenotypic and immunogenotypic B-cell differentiation arrest in bone marrow of RAG deficient SCID patients corresponds to residual recombination activities of mutated RAG proteins. Blood. 2002;100:2145-2152.

23. Noordzij JG, De Bruin-Versteeg S, Comans-Bitter WM, et al. Composition of the precursor B-cell compartment in bone marrow from patients with X-linked agammaglobulinemia compared to healthy children. Pediatr Res. 2002;51:159-168.

24. Tsuganezawa K, Kiyokawa N, Matsuo Y, et al. Flow cytometric diagnosis of the cell lineage and developmental stage of acute lymphoblastic leukemia by novel monoclonal antibodies specific to human pre-B-cell receptor. Blood. 1998;92:43174324.

25. Groeneveld K, Te Marvelde JG, Van den Beemd MW, Hooijkaas H, Van Dongen JJM. Flow cytometric detection of intracellular antigens for immunophenotyping of normal and malignant leukocytes. Leukemia. 1996;10:1383-1389.

26. Van Lochem EG, Groeneveld K, Te Marvelde JG, Van den Beemd MW, Hooijkaas H, Van Dongen JJM. Flow cytometric detection of intracellular antigens for immunophenotyping of normal and malignant leukocytes: testing of a new fixationpermeabilization solution. Leukemia. 1997;11: 2208-2210.

27. Dronkert ML, de Wit J, Boeve M, et al. Disruption of mouse SNM1 causes increased sensitivity to the DNA interstrand cross-linking agent mitomycin C. Mol Cell Biol. 2000;20:4553-4561. 